\title{
BMJ Global Health Universal access to essential health information: accelerating progress towards universal health coverage and other SDG health targets
}

\author{
Geoff Royston (1) , ${ }^{1}$ Neil Pakenham-Walsh, ${ }^{2}$ Chris Zielinski ${ }^{3}$
}

To cite: Royston G,

Pakenham-Walsh $\mathrm{N}$,

Zielinski C. Universal access to essential health information: accelerating progress towards universal health coverage and other SDG health targets. BMJ Global Health 2020;5:e002475. doi:10.1136/ bmjgh-2020-002475

Handling editor Seye Abimbola

Received 12 March 2020

Revised 22 April 2020

Accepted 23 April 2020

Check for updates

(C) Author(s) (or their employer(s)) 2020. Re-use permitted under CC BY-NC. No commercial re-use. See rights and permissions. Published by BMJ.

${ }^{1}$ Independent, Harrogate, UK ${ }^{2}$ Healthcare Information for All, Global Healthcare Information Network, Charlbury, UK

${ }^{3}$ Centre for Global Health, University of Winchester, Winchester, UK

Correspondence to Dr Geoff Royston; geoff.royston@gmail.com

\section{ABSTRACT}

The information that people need to protect and manage their own health and the health of those for whom they are responsible is a fundamental element of an effective people-centred healthcare system. Achieving universal health coverage $(\mathrm{UHC})$ requires universal access to essential health information. While it was recently recognised by the World Medical Association, universal access to essential health information is not yet reflected in official monitoring of progress on UHC for the sustainable development goals (SDGs). In this paper, we outline key features that characterise universal access to essential health information and indicate how it is increasingly achievable. We highlight the growing evidence of the impact of wider access to practical and actionable information on health for the public, carers and frontline health workers and provide illustrative, evidence-based, examples of how increasing access to essential health information can accelerate the achievement of UHC and other health targets of the SDGs. The paper ends with an assessment of reasons why universal access to essential health information has not yet been achieved, and an associated call to action to key stakeholders - such as governments, multilaterals, funding bodies, policy-makers, health professionals and knowledge intermediaries - to explicitly recognise the foundational role of universal access to essential health information for achieving UHC and the rest of the health SDGs, to include it in the relevant SDG target and associated monitoring indicators, and to incorporate actions in their own policies and programmes to promote and enable this access.

\section{INTRODUCTION}

The protection of the health of any individual or population, including the prevention and appropriate management of disease, is fundamentally dependent on the availability and use of reliable health information (see figure 1). (Although 'health information' is sometimes used to refer to data only, especially that used by managers and policy-makers, in this paper health information refers to practical information, especially that used by the public and health workers, for health and healthcare.)
Summary box

- Effective people-centred healthcare requires the public, carers and frontline health workers to have timely access to reliable, practical, health information (we term this essential health information), yet in many parts of the world this is often difficult for people to obtain.

- Universal access to essential health information is therefore a prerequisite for, and indeed a key component of, universal health coverage (UHC), yet this fundamental role for UHC of access to essential health information appears to have been largely neglected-for example, it does not feature in the sustainable development goal (SDG) UHC target or associated indicators.

- There is growing evidence of the impact of wider access to practical, actionable, information about health and how this could accelerate the achievement of UHC and other SDG health targets.

- Achieving universal access to essential health information is becoming increasingly feasible and affordable, not least due to the global spread of modern communication technology, but progress is being held back by a glaring lack of high-level political and financial commitment.

- All stakeholders need to work together to accelerate progress towards universal access to essentia health information; a catalyst for this would be the inclusion of universal access to essential health information in the relevant SDG target and associated monitoring indicators for UHC, a step that WHO could usefully endorse.

The need to improve individuals' access to health information, to give better support to people-centred care, is indicated by recent statements by international bodies, for example, the UNICEF/WHO Vision for Primary Health Care in the 21st century ${ }^{1}$ includes the aim that 'People have access to the knowledge, skills and resources needed to care for themselves and their loved ones'. That requires the public, carers and frontline 


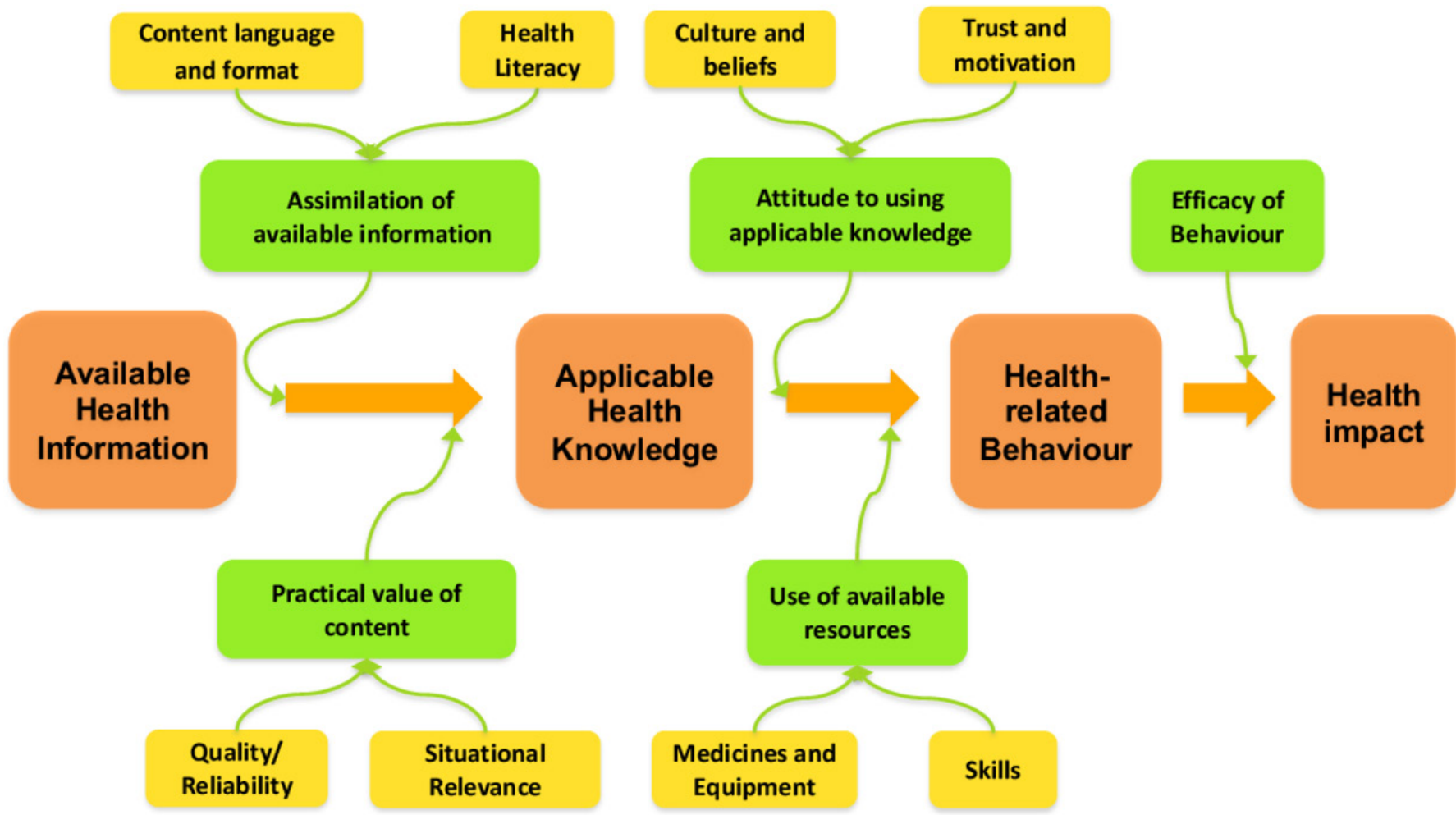

Figure 1 The fundamental role of information and knowledge in a person's health pathway.

health workers to have timely access to reliable 2 practical, actionable, health information.

We term this essential health information - the information that people need to protect their own health and the health of those for whom they are responsible. It includes information and knowledge to promote health and to prevent, diagnose and manage disease and injury. It acknowledges that, especially in low-income and middle-income countries, most avoidable mortality and morbidity can be prevented through the application of basic health knowledge (eg, on using amoxicillin for child pneumonia; on the need for oral rehydration for acute diarrhoea; about healthy lifestyle choices to prevent cardiovascular disease, cancer, respiratory disease and diabetes). See table 1 .

Given the key role of such information for health, the Healthcare Information For All network (HIFA) has argued, ${ }^{2}$ and the World Medical Association has recently issued a supportive statement, ${ }^{3}$ that universal access to essential health information is a prerequisite for universal health coverage (UHC). Indeed, from a 'whole system' perspective-explicitly a key feature of the sustainable development goals (SDGs) - it should be seen as a key component of UHC. Such access is therefore also a prerequisite for attaining the SDG on health (SDG3) and associated targets, especially of course the UHC target (SDG 3.8 'Achieve universal health coverage, including financial risk protection, access to quality essential health-care services and access to safe, effective, quality and affordable essential medicines and vaccines for all'.)

\section{EVIDENCE OF THE IMPACT OF WIDER ACCESS TO HEALTH INFORMATION}

A government survey, published in $2006,{ }^{4}$ found that only 4 in 10 children in India received any form of oral rehydration therapy (ORT) if they developed diarrhoea. Areas where knowledge of ORT was greater tended also to be to those where its use was greater. The next national survey, in $2015,{ }^{5}$ showed that more women in India knew about ORT than before and the proportion of children with diarrhoea who received it had now risen to 6 in 10 . Other investigations also have indicated positive impacts from the provision of information about appropriate care in such cases; for example, use of the HealthPhone mobile app has been associated with improvements in increased use of oral rehydration during diarrhoea episodes, and of increased frequency of handwashing, breast feeding and immunisation. ${ }^{6}$

There are now an increasing number of evaluations and, more recently, reviews of evaluations, being published on the impact of making essential health information more accessible, especially via mobile phones, for example. ${ }^{7}$ Impact studies in LMICs, at least for mHealth, are increasing and there are now several systematic reviews of mHealth in areas such as maternal and neonatal care, ${ }^{89}$ and non-communicable diseases and public health. ${ }^{10} 11$ Many of these studies focus on provision of health information.

Drawing on the development of such evidence, WHO has recently published guidance ${ }^{12}$ on use of digital interventions, including those providing health information, 
Table 1 Characteristics of essential health information

\begin{tabular}{|c|c|}
\hline Characteristic & Comment \\
\hline Applicable & $\begin{array}{l}\text { To be useful to the public, carers and frontline health workers, health information needs to be } \\
\text { applicable, that is, relevant to tackling a practical health problem, culturally acceptable, appropriate to } \\
\text { local practice and availability of medicines and facilities, and actionable. }\end{array}$ \\
\hline Diverse & $\begin{array}{l}\text { Health information needs to cover of a wide variety of people (eg, individuals, families, carers, health } \\
\text { workers) and a range of issues for example, common life-threatening diseases, health emergencies. } \\
\text { The health information needs of the individual are context dependent - that is, they depend on } \\
\text { the given situation at any given time. Every person has health information needs, whether in high- } \\
\text { income countries or low-to-middle income countries (LMICs). In LMICs, these needs are especially } \\
\text { important because there is less access to actionable, reliable information and less access to health } \\
\text { professionals. }\end{array}$ \\
\hline Reliable & $\begin{array}{l}\text { By 'reliable' we mean that the information is based on an objective interpretation of the available } \\
\text { evidence. Misinformation, whether unintentional or deliberate, is a serious health hazard, as } \\
\text { experiences, for example, with vaccination, }{ }^{33} \mathrm{Ebola}^{34} \text { and coronavirus, }{ }^{35} \text { sadly demonstrate. Biased } \\
\text { information can also result consciously or unconsciously from 'expert opinion' and from commercial } \\
\text { motives (including pharmaceutical advertising). }\end{array}$ \\
\hline Comprehensible & $\begin{array}{l}\text { Even if reliable information is available, it may not be understandable or assimilated by its recipients } \\
\text { if its provision is too technical, or in the wrong language, or an inappropriate form (eg, only in text } \\
\text { where literacy levels are low). For example, people with low literacy have been found to have a one } \\
\text { in three chance of misunderstanding prescribed medication. }{ }^{36} \text { To improve the assimilation of health } \\
\text { information, we need also to improve health literacy, or 'the degree to which individuals have the } \\
\text { capacity to obtain, process, and understand basic health information and services needed to make } \\
\text { appropriate health decisions'. }{ }^{37} \text { It is also critical that providers of health information have a clear } \\
\text { understanding of the health literacy of their audiences, and ensure that such information will be } \\
\text { intelligible across the widest range possible of health literacy levels. }\end{array}$ \\
\hline
\end{tabular}

and made recommendations including one specifically relating to information provision for the public and carers: "WHO recommends targeted client communication via mobile devices for behaviour change regarding sexual, reproductive, maternal, newborn and child health, under the condition that concerns about sensitive content and data privacy are adequately addressed" (p59).

Of course, not all evaluations in this area reveal positive results. For example, some trials of text messaging have not shown any impact on health-related behaviour, see, for example, Linnemayr et al. ${ }^{13}$ But there are many examples of success, indicating considerable potential for wider access to essential health information to contribute to progress on SDG health targets. Some specific evaluated examples are given in the next section.

\section{UNIVERSAL ACCESS TO ESSENTIAL HEALTH INFORMATION AND PROGRESS ON UHC AND OTHER SDG HEALTH TARGETS}

The world faces a major challenge in meeting the SDG targets, not least the SDG 3.8 target for UHC by 2030 , which WHO estimates (WHO General Work Programme 2019-2023 para 32) will require a doubling or tripling of the current pace of change.

Universal access to essential health information is an important component of the package of measures that will be necessary to increase the pace of change towards UHC and other SDG3 targets. Access to essential health information can be an accelerator for many of the components of UHC monitored for SDG 3.8.1, other SDG3 health targets and health literacy.

This key point is developed and illustrated in tables 2 and 3 .

The first column of table 2 shows the framework, ${ }^{14}$ comprising a set of areas of health, currently being used or considered for use by the UN to monitor progress towards UHC. Progress in most if not all of these areas would be supported by universal access to essential health information. For example, enhancement of care-seeking rates in pregnancy and childhood illness, by families having access to information on when and how care should be sought. We give further examples in the second column of table 2. We chose these examples not least because all of this information, and more, in many LMICs, already exists, though often is not yet widely accessible, in traditional or digital media.

In table 3, we provide documented evidence-based illustrations of how provision of practical health information in the target areas described in table 2 can contribute to achieving the SDG3 targets on specific health issues and progress towards UHC as monitored by the associated SDG indicators.

\section{LACK OF ACCESS TO ESSENTIAL HEALTH INFORMATION IS A NEGLECTED ISSUE IN THE SDG UHC TARGET}

Unfortunately, in many parts of the world, it is often difficult for people to obtain essential health information. This needs to be accessible: 
Table 2 Examples of practical health information relevant to target areas in the UN monitoring framework for universa health coverage (UHC)

\begin{tabular}{|c|c|}
\hline $\begin{array}{l}\text { Target area for UHC (SDG } \\
\text { 3.8.1) }\end{array}$ & $\begin{array}{l}\text { Examples of practical } \\
\text { information for empowering } \\
\text { the public and frontline } \\
\text { health workers to progress } \\
\text { this target area }\end{array}$ \\
\hline \multicolumn{2}{|l|}{ Mother and child health } \\
\hline Family planning & $\begin{array}{l}\text { - Timing births } \\
\text { - Family planning methods }\end{array}$ \\
\hline $\begin{array}{l}\text { Pregnancy and delivery of } \\
\text { care }\end{array}$ & $\begin{array}{l}\text { Staying healthy during } \\
\text { pregnancy } \\
\text { Danger signs during } \\
\text { pregnancy and during birth } \\
\text { How to carry out basic } \\
\text { tests and treatments } \\
\text { Care during pregnancy } \\
\text { Breast feeding } \\
\text { Managing labour and } \\
\text { delivery }\end{array}$ \\
\hline Child immunisation & $\begin{array}{l}\text { Immunising your child in } \\
\text { the first year of life }\end{array}$ \\
\hline Child treatment & $\begin{array}{l}\text { Using oral rehydration } \\
\text { solution }\end{array}$ \\
\hline
\end{tabular}

Infectious disease

\begin{tabular}{|c|c|}
\hline Tuberculosis treatment & - Tuberculosis prevention \\
\hline HIV treatment & $\begin{array}{l}\text { Prevention and treatment } \\
\text { of HIV }\end{array}$ \\
\hline Malaria prevention & $\begin{array}{l}\text { Environmental control } \\
\text { Use of insecticides and } \\
\text { treated nets } \\
\text { Malaria prevention }\end{array}$ \\
\hline Water and sanitation & $\begin{array}{l}\text { Water filtration } \\
\text { Cholera prevention } \\
\text { Effective handwashing } \\
\text { Hygiene and sanitation in } \\
\text { schools and workplaces }\end{array}$ \\
\hline \multicolumn{2}{|l|}{$\begin{array}{l}\text { Non-communicable } \\
\text { diseases }\end{array}$} \\
\hline $\begin{array}{l}\text { Prevention of cardiovascular } \\
\text { disease }\end{array}$ & Dangers of smoking \\
\hline Management of diabetes & $\begin{array}{l}\text { How to handle a diabetic } \\
\text { emergency }\end{array}$ \\
\hline $\begin{array}{l}\text { Cancer detection and } \\
\text { treatment }\end{array}$ & $\begin{array}{l}\text { Risk factors for cancers } \\
\text { Problems in diagnosing } \\
\text { cancers } \\
\text { Treatment and care of } \\
\text { common cancers }\end{array}$ \\
\hline Tobacco control & Smoking cessation \\
\hline
\end{tabular}

SDG, sustainable development goal.

- to the relevant person (eg, individual, carer or frontline health worker),

- in a given location (eg, a remote village),
- at the time it is most needed (eg, an emergency),

- through a suitable medium (eg, print, radio, TV, phone, internet),

- at an affordable (preferably zero) cost.

Despite the importance of access to such information, and hence of addressing the challenges of lack of access, this does not feature in the SDG target on UHC or the associated current set of indicators ${ }^{15}$ for assessing progress towards the target. (It is mentioned only in relation to one specific aspect of healthcare in a related target (SDG 3.7) "ensure universal access to sexual and reproductive health-care services, including for family planning, information and education...").

As noted ${ }^{16}$ by HIFA, the UHC target (SDG 3.8) could be made more consistent with current WHO policies and guidelines on primary care by adding just two words (shown in bold) to it, that is: "Achieve universal health coverage, including financial risk protection, access to quality essential health-care services [and information], and access to safe, effective, quality and affordable essential medicines and vaccines for all"; and to similarly include "access to essential health information" in the corresponding monitoring indicator (SDG 3.8.1)

The current omission of access to essential health information from the SDG UHC target has important practical consequences. First, and directly, it inhibits the development of the tools and indicators needed to measure progress in expanding the access to and use of essential health information. Second, and fundamentally, it misses an opportunity to give international impetus to improving access to essential health information at global, national and local levels. This is especially needed in LMICs, to ensure that frontline health workers are adequately informed and that people are empowered with the knowledge they need to be active in their own health.

\section{ACHIEVING UNIVERSAL ACCESS TO ESSENTIAL HEALTH INFORMATION IS INCREASINGLY FEASIBLE}

Access to health information depends on the workings of the global health information system, that is, the system by which reliable health information is created, (re)packaged and then made available, as outlined in figure 2, and how this plays out in different settings.

There are now major opportunities for improving this system, not least for improving access to reliable, practical, health information that already exists. There is now a range of simple, affordable and scalable ${ }^{17}$ routes for widening such access.

First, traditional routes of getting health information into the hands of those who most need it, typically through printed (for example, the guide Where there is No Doctor ${ }^{18}$ ), or other long-established media, for example, radio and film. Indeed, radio messaging has been part of the public health armoury for decades, and organisations such as Medical Aid Films ${ }^{19}$ and Global Health Media ${ }^{20}$ have been producing open access audio and video content in local 
Table 3 Illustrative examples of the potential contribution of access to essential health information to achieving sustainable development goal (SDG3) health targets

SDG3 health target

Illustration of potential contribution of access to essential health information to achieving this target and/or to the indicators of progress on UHC (SDG3.8.1) associated with

it

3.2 By 2030 , end preventable deaths of newborns and children under 5 years of age, with all countries aiming to reduce neonatal mortality to at least as low as 12 per 1000 live births and under-5 mortality to at least as low as 25 per 1000 live births.

(This area is already the subject of a recent WHO recommendation on using mobiles for targeted communication; see text)
Control trial studies ${ }^{3839}$ of use by healthcare workers of a safe delivery information smartphone app in Ethiopia and of mobile phone text messaging for pregnant women in Zanzibar indicated associated reductions in perinatal infant mortality from 23 to 14 and from 36 to 19 per 1000 , respectively. A cluster randomised trial ${ }^{40}$ of a child health radio campaign in Burkina Faso showed increases of consultations for pneumonia of $39 \%$ and for diarrhoea by $73 \%$ and lives saved modelling with LiST indicated an average reduction in under-5 mortality of $7 \%$ per year.

3.3 By 2030, end the epidemics of AIDS, tuberculosis, malaria A Cochrane review ${ }^{41}$ of randomised control trials on use of text and neglected tropical diseases and combat hepatitis, waterborne diseases and other communicable diseases.

messaging for adherence to antiretroviral therapy in patients in Kenya with HIV infection showed treatment adherence
3.4 By 2030 , reduce by one-third premature mortality treatment and promote mental health and well-being from non-communicable diseases through prevention and rates and viral load suppression rates both improved, from a baseline of about $50 \%$ in the control to $60 \%$ in the messaging group.

A systematic review ${ }^{42}$ of mobile phone apps related to HIV in Africa found numerous examples of improved adherence to medication and attendance to scheduled appointments through SMS and voice calls.

A control study ${ }^{43}$ of text messaging malaria treatment guidelines to health workers in in Kenya showed an improvement in correct case management from a $20 \%$ baseline to $51 \%$ (about $45 \%$ after control group correction)

A systematic review ${ }^{44}$ of nine articles addressing the impact of $\mathrm{m}$-health (mostly SMS texting or interactive phone applications) on outcomes of chronic diseases in LMICs found it to be cost effective and to have modest but positive impacts on processes of care, clinical outcomes and health-related quality of life.

Results from independent evaluations ${ }^{45}$ of $\mathrm{WHO}$ and International Telecommunication Union's Be He@lthy, Be Mobile programs show a $19 \%$ quit rate among a large sample of participants in the mTobaccoCessation project, drawn from the 2.1 million people in India receiving SMS messaging on tobacco cessation. Such services appear 2-3 times as effective as traditional cessation services alone.

3.6 By 2020 , halve the number of global deaths and injuries from road traffic accidents.
It has been estimated that some $40 \%$ of road traffic accident deaths could be prevented by immediate road-side first aid ${ }^{46}$ yet public knowledge of appropriate first aid is very low in almost every country. Education in first aid has been shown ${ }^{47}$ to increase such knowledge considerably, for example, by a factor of 3. (Practical first aid information is now available to people in many countries, in their own language, via the Red Cross/Red Crescent First Aid mobile app but penetration and use appear to be minimal.) 
3.7 By 2030, ensure universal access to sexual and reproductive healthcare services, including for family planning, information and education, and the integration of reproductive health into national strategies and programmes. (This area is already the subject of a recent WHO recommendation on using mobiles for targeted communication; see text)
A randomised control trial ${ }^{48}$ of an educational campaign for pregnant women on healthy timing and spacing of pregnancy carried out by community workers using simple communication materials (leaflets, posters, wall paintings and booklets), found use of effective contraception methods increased from $30 \%$ in the control group to $57 \%$ in the intervention group.

A control tria ${ }^{49}$ on use of infographics for educating women in Iran about different forms of contraception showed their knowledge of the relative effectiveness of different contraceptive methods increased from a baseline of $50 \%-80 \%$ or above.

A randomised control trial ${ }^{50}$ in Kenya of text messaging about postpartum family planning showed use of highly effective contraceptive methods increased from $57 \%$ in the control group to $70 \%$ in the intervention group.

UHC, universal health coverage.

languages, in collaboration with international health organisations such as WHO and UNICEF, for many years. The reach of these now extends to films on a wide range of topics (such as nutrition, pregnancy, newborn care, child health, infectious diseases like cholera or Ebola), in dozens of languages, available in hundreds of countries, with millions of views each year.

Second, the digital revolution offers huge potential to advance access to essential health information, among a range of contributions towards $\mathrm{UHC}^{21}$ On 26 May 2018, "recognizing the potential of digital technologies to advance the Sustainable Development Goals", the World Health Assembly passed a resolution on Digital Health (A71-R7) urging Member States "to prioritize, as appropriate, the development, evaluation, implementation, scale-up and greater utilization of digital technologies, as a means of promoting equitable, affordable and universal access to health for all”.

Multiple digital routes are opening up to provide this access. For example, WikiMed provides free, offline, digital access, for example, on laptops, tablets or mobile phones, to all of Wikipedia's health content. Of particular importance for the public and carers is access to health

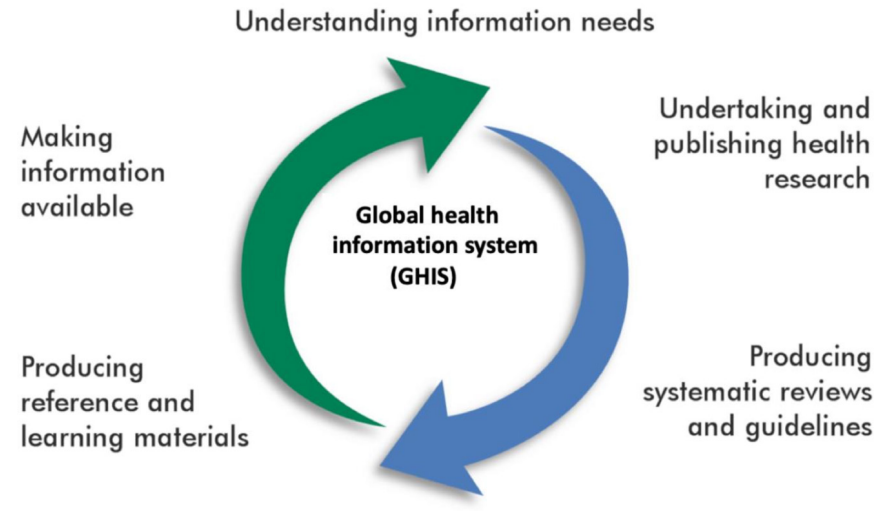

Figure 2 The global health information system. *Figure adapted from Godlee et al, ${ }^{29}$ information through mobile phones $^{22}$ which are now ubiquitous, not least in LMICs (as the WHO Vision for Primary Care in the 21st Century, page 21, notes: "Today ... the first thing that many people across the world do when faced with a health problem is to use their mobile phone to seek more information"). For example:

- For people with access to basic phones: SMS texting, such as in the MomConnect maternal health service used by 2 million women in South Africa, ${ }^{23}$ is already a wellestablished pathway for 'provider push' distribution of health messages. Essential health information can also be provided through 'user pull' pathways (such as free or subsidised voice-on-demand services) which empower the public and carers to get the health information they want, in a form they can use, when and where they need it. These services respond with (usually prerecorded) audio messages in local languages to user requests for health information on a range of key heath topics. A few organisations already provide such services (eg, 3-2-1 (Viamo/ Human Network International), ${ }^{24}$ Mobile Kunji (BBC Media Action). ${ }^{25}$

- For (the rapidly increasing number of) people with access to feature or smartphones: essential health information for the public and carers can be provided in a user pull mode through mobile 'apps', many of which, once downloaded, will function even without a network connection. Such applications often include short practical 'how to' videos that are accessible to all irrespective of literacy level. Notable examples (and the organisations that produce them) include: First Aid (Red Cross), ${ }^{26}$ HealthPhone (Mother and Child Trust) ${ }^{27}$; Safe Pregnancy and Birth (Hesperianpublisher of Where There is No Doctor). ${ }^{28}$

\section{A CALL TO ACTION}

Why have we not achieved universal access to essential health information? There are at least two reasons. The 
first is that there is no single fix, no 'magic bullet'. As previously described, ${ }^{29}$ the availability and use of reliable health information are dependent on the integrity of the global health information system. A systemsthinking approach to the issue readily demonstrates the vital inputs of a huge number and diversity of 'components', including health research per se, publication and dissemination of such research, systematic review, guideline development and the myriad of different secondary outputs for end-users.

However, there are important system leverage points, ${ }^{30}$ one of which (a focus of this paper) is improving access to reliable, practical health information that already exists. The second reason is related to the first: lack of recognition by governments and funding agencies of the fundamental importance of access to essential health information, and consequent lack of investment.

We therefore call on all stakeholders-including governments, multilaterals (WHO, World Bank, UNESCO, UNICEF, International Labour Organization, International Telecommunication Union and others), funding bodies, policy-makers, health professionals and knowledge intermediaries-to work together to accelerate progress towards universal access to essential health information.

This could include assessing, in each country, the level of access, by traditional and by digital pathways, to essential health information; agreeing, steps, appropriate to that country, that could be best taken rapidly to increase such access; and then actioning them. (This could be stimulated by adding access to essential health information to the UHC target (SDG3.8) and/or to the corresponding monitoring indicator (SDG3.8.1) for service coverage, a step that WHO could usefully endorse.)

In the past 20 years, WHO has led and enabled a number of important initiatives, such as the Hinari Access to Research in Health Programme, to improve the availability of health information. It is uniquely placed to facilitate further action over the years to come. In 2006, WHO wrote a letter of support for the launch of the global campaign, HIFA (www.hifa.org), which stated: "Healthcare Information For All is an ambitious goal, but it can be achieved if all stakeholders work together". We, together with the 20000 members of HIFA, representing all stakeholder groups in almost every country, and working in formal collaboration with WHO to support global health communication in multiple languages, look forward to continue working with WHO and others to make universal access to essential health information a reality.

\section{CONCLUSION}

We have argued that universal access to essential health information is a prerequisite for, and indeed a component of, UHC and have presented illustrative examples as evidence of how enhancing such access can serve as an accelerator for achieving UHC and the other health
SDGs. We have argued that universal access is not only necessary, but is increasingly feasible and affordable, not least because of advances in communication technology: what has been termed the 15th Grand Challenge for Global Health-'to ensure that everyone in the world can have access to clean, clear, knowledge ${ }^{31}$ - is well within reach. (We note also that governments that are party to treaties such as the International Covenant on Civil and Political Rights, that is, almost all governments, 'must provide and guarantee access to health information, ${ }^{32}$ ) However, we have also noted that overall progress is being held back by a glaring lack of high-level political and financial commitment.

Acknowledgements The authors are grateful to all HIFA members who have contributed their experience and expertise to ongoing discussions on the HIFA forums over recent years. These contributions have helped the authors and the HIFA Steering group to articulate the points made in this paper. Special thanks to members of the HIFA Steering Group who have commented on drafts of the paper. Current members of the HIFA Steering Group (23 February 2020) are: Tara Ballav Adhikari, Grace Ajuwon, Najeeb Al-Shorbaji, Joseph Ana, Frederick Bukachi, Martin Carroll, Sarah Cavanagh, Tracy Eastman, Alberto Fernández Ajuria, Liz Grant, Arthy Hartwell, John Liebhardt, Wendie Norris, Oluwatosin Ogunmoyero, Onikepe Oluwadamilola Owolabi, Neil Pakenham-Walsh, Jonathan Parker, Karah Pedersen, Eliane Pereira dos Santos, Julie N Reza, Ian Roberts, Geoff Royston, Rachel Stancliffe, Julie Storr, Arjun Thandi, Isabelle Wachsmuth-Huguet, Nand Wadhwani, Tony Waterston, Chris Zielinski. For affiliations and profiles, see http:// www.hifa.org/people/steering-group. They also acknowledge helpful suggestions on improving the manuscript from an anonymous referee.

Contributors GR proposed the paper and produced a first rough draft. GR, NP-W and $\mathrm{CZ}$ all worked on developing and revising further drafts. All authors approved the final version.

Funding Healthcare Information For All is currently funded (2020) through contributions from 35 health and development organisations worldwide. Full lists of current and past funders are available here: http://www.hifa.org/support/donate.

Competing interests None declared.

Patient consent for publication Not required.

Provenance and peer review Not commissioned; externally peer reviewed.

Data availability statement There are no data in this work.

Open access This is an open access article distributed in accordance with the Creative Commons Attribution Non Commercial (CC BY-NC 4.0) license, which permits others to distribute, remix, adapt, build upon this work non-commercially, and license their derivative works on different terms, provided the original work is properly cited, appropriate credit is given, any changes made indicated, and the use is non-commercial. See: http://creativecommons.org/licenses/by-nc/4.0/.

\section{ORCID iD}

Geoff Royston http://orcid.org/0000-0001-7180-3124

\section{REFERENCES}

1 World Health Organization and UNICEF. A vision for primary care in the 21st century: towards universal health coverage and the sustainable development goals. Geneva: World Health Organization and United Nations Children's Fund, 2018: 46p. https://www.who. int/docs/default-source/primary-health/vision.pdf

2 Healthcare Information for All. HIFA, universal health coverage and human rights, 2020. Available: http://www.hifa.org/about-hifa/hifauniversal-health-coverage-and-human-rights [Accessed 19 Feb 2020].

3 Pakenham-Walsh N, Godlee F. Healthcare information for all. BMJ 2020;368:m759.

4 Ministry of Health and Family Welfare Government of India. National Family Health Survey (NFHS-3) 2005/6 2005.

5 Ministry of Health and Family Welfare Government of India. National family health survey (NFHS-4) 2015/16 2015. 
6 Yadav S, Rawai G. The HIFA and the HealthPhone: laying the foundation for combating malnutrition in India.. International Journal of Health Science and Research 2015;5:368-71.

7 Hall CS, Fottrell E, Wilkinson S, et al. Assessing the impact of mHealth interventions in low- and middle-income countries--what has been shown to work? Glob Health Action 2014;7:25606.

8 Lee SH, Nurmatov UB, Nwaru BI, et al. Effectiveness of mHealth interventions for maternal, newborn and child health in low- and middle-income countries: systematic review and meta-analysis. $J$ Glob Health 2016;6:010401.

9 Sondaal SFV, Browne JL, Amoakoh-Coleman M, et al. Assessing the effect of mHealth interventions in improving maternal and neonatal care in low- and middle-income countries: a systematic review. PLoS One;11:e0154664 https://doi.org/

10 Stephani V, Opoku D, Quentin W. A systematic review of randomized controlled trials of mHealth interventions against non-communicable diseases in developing countries. BMC Public Health 2016;16:572.

11 Müller AM, Alley S, Schoeppe S, et al. The effectiveness of e-\& mHealth interventions to promote physical activity and healthy diets in developing countries: A systematic review. Int J Behav Nutr Phys Act 2016;13:109.

12 World Health Organization. Who guideline: recommendations on digital interventions for health system strengthening. Geneva: World Health Organization, 2019: 150.

13 Linnemayr $\mathrm{S}$, Huang $\mathrm{H}$, Luoto $\mathrm{J}$, et al. Text messaging for improving antiretroviral therapy adherence: no effects after 1 year in a randomized controlled trial among adolescents and young adults. Am J Public Health 2017;107:1944-50.

14 Hogan DR, Stevens GA, Hosseinpoor AR, et al. Monitoring universal health coverage within the sustainable development goals: development and baseline data for an index of essential health services. Lancet Glob Health 2018;6:e152-68 https://doi.org/

$15 \mathrm{WHO}$. Metadata for tracer indicators used to measure the coverage of essential health services for monitoring SDG indicator 3.8.1, 2018. Available: https://www.who.int/healthinfo/universal_health_coverage/ UHC Tracer Indicators Metadata.pdf [Accessed 20 Apr 2020].

16 HIFA. HIFA marks World health day with call to target and track progress on universal access to essential healthcare information, 2018. Available: http://www.hifa.org/news/hifa-marks-world-healthday-call-target-and-track-progress-universal-access-essential [Accessed 20 Apr 2020].

17 Labrique AB, Wadhwani C, Williams KA, et al. Best practices in scaling digital health in low and middle income countries. Global Health 2018;14:103.

18 Hesperian. The new where there is no doctor, 2019. Available: https://en.hesperian.org/hhg/New_Where_There_Is_No_Doctor [Accessed 20 Apr 2020].

19 Medical Aid Films. What we do, 2020. Available: https://www. medicalaidfilms.org/learn/what-we-do-2/ [Accessed 20 Apr 2020].

20 Global Health Media. What we do, 2020. Available: https:// globalhealthmedia.org/what-we-do/meeting-the-need/ [Accessed 20 Apr 2020].

21 Olu O, Muneene D, Bataringaya JE, et al. How can digital health technologies contribute to sustainable attainment of universal health coverage in Africa? A perspective. Frontiers in Public Health 2019;7:1-7.

22 Royston G, Hagar C, Long L-A, et al. Mobile health-care information for all: a global challenge. Lancet Glob Health 2015;3:e356-7.

23 Department of Health. Republic of South Africa. MomConnect, 2020. Available: http://www.health.gov.za/index.php/mom-connect [Accessed 22 Apr 2020].

24 Viamo. Try the 3-2-1 Service - Nigeria, 2020. Available: https:// viamo.io/information-sharing/try-the-3-2-1-service-nigeria/ [Accessed 22 Apr 2020].

25 BBC Media Action. Mobile Kunji, 2020. Available: https://www. rethink1000days.org/programme-outputs/mobile-kunji/ [Accessed 22 Apr 2020].

26 Red Cross/Red Crescent Global Disaster Preparedness Canter. First Aid App, 2020. Available: https://www.preparecenter.org/activities/ first-aid-app [Accessed 22 Apr 2020].

27 The Mother and Child Health and Education Trust. HealthPhone, 2020. Available: http://www.healthphone.org/ [Accessed 22 Apr 2020].
28 Hesperian Health Guides. Safe pregnancy and birth app, 2020. Available: https://hesperian.org/books-and-resources/safepregnancy-and-birth-mobile-app/ [Accessed 22 Apr 2020].

29 Godlee F, Pakenham-Walsh N, Ncayiyana D, et al. Can we achieve health information for all by 2015? Lancet 2004;364:295-300.

30 Meadows DH. Leverage Points - Places to Intervene in a System. In: Meadows DH, ed. Thinking in systems. London: Earth Scan, 2009: 145-65.

31 Pang T, Gray M, Evans T. A 15th grand challenge for global public health. The Lancet 2006;367:284-6.

32 Institute for Information Law and Policy. Access to health information under international human rights law, white paper series 11/12 No.1 2012.

33 Burki T. Vaccine misinformation and social media. Lancet Digit Health 2019:1:e258-9.

34 Hayden S. How Misinformation is Making it Almost Impossible to Contain the Ebola Outbreak in DRC. TIME, 2019. Available: https:// time.com/5609718/rumors-spread-ebola-drc/ [Accessed 20 Apr 2020].

35 Department for International Development. UK aid to tackle global spread of coronavirus 'fake news', 2020. Available: https://www.gov. uk/government/news/uk-aid-to-tackle-global-spread-of-coronavirusfake-news [Accessed 20 Apr 2020].

36 Wolf MS, Davis TC, Shrank W, et al. To err is human: patient misinterpretations of prescription drug label instructions. Patient Educ Couns 2007:67:293-300.

37 National Network of Libraries of Medicine. Health literacy definition, 2020. Available: https://nnlm.gov/initiatives/topics/health-literacy [Accessed 25 Feb 2020].

38 Lund S, Boas IM, Bedesa T, et al. Association between the safe delivery APP and quality of care and perinatal survival in Ethiopia: a randomized clinical trial. JAMA Pediatr 2016;170:765-71.

39 Lund S, Rasch V, Hemed M, et al. Mobile phone intervention reduces perinatal mortality in Zanzibar: secondary outcomes of a cluster randomized controlled trial. JMIR Mhealth Uhealth 2014;2:e15.

40 Murray J, Head R, Sarrassat S, et al. Modelling the effect of a mass radio campaign on child mortality using facility utilisation data and the lives saved tool (list): findings from a cluster randomised trial in Burkina Faso. BMJ Glob Health 2018;3:e00080:e000808.

41 Horvath T, Azman H, Kennedy GE, et al. Mobile phone text messaging for promoting adherence to antiretroviral therapy in patients with HIV infection. Cochrane Database Syst Rev 2012;2012:CD009756

42 Linguissi LSG, Ouattara AK, Ntambwe EK, et al. Mobile applications: effective tools against HIV in Africa. Health and Technology 2017;4:1-8

43 Zurovac D, Sudoi RK, Akhwale WS, et al. The effect of mobile phone text-message reminders on Kenyan health workers' adherence to malaria treatment guidelines: a cluster randomised trial. Lancet 2011;378:795-803.

44 Beratarrechea A, Lee AG, Willner JM, et al. The impact of mobile health interventions on chronic disease outcomes in developing countries: a systematic review. Telemed J E Health 2014;20:75-82.

45 Gopinathan P, Kaur J, Joshi S, et al. Self-Reported quit rates and quit attempts among subscribers of a mobile text messagingbased tobacco cessation programme in India. BMJ Innovations 2018;4:147-54

46 Hussain LM, Redmond AD. Are pre-hospital deaths from accidental injury preventable? BMJ 1994;308:1077-80.

47 El-Sharkasy MH, Shenouda MS, El-Sheikh EL. Impact of first aid training program for CAR drivers about road traffic injuries in Port said. Med J Cairo Univ 2015;83:135-43.

48 Sebastian MP, Khan ME, Kumari K, et al. Increasing postpartum contraception in rural India: evaluation of a community-based behavior change communication intervention. Int Perspect Sex Reprod Health 2012;38:068-77.

49 Mohammad-Alizadeh-Charandabi S, Shahnazi M, Jahanbakhsh R. Communicating contraceptive effectiveness: a randomized controlled trial. J Caring Sci 2012;1:1-9.

50 Harrington EK, Drake AL, Matemo D, et al. An mHealth SMS intervention on postpartum contraceptive use among women and couples in Kenya: a randomized controlled trial. Am J Public Health 2019;109:934-41. 